\title{
Contaminação microbiológica de resinas compostas utilizadas em uma clínica-escola de Odontologia
}

\author{
Haroldo José Mendes*; Patricia Elizabeth Souza Matos*; Fabio Ornellas Prado*; Tassia Pina Silva \\ Freire $^{* *}$; Herbert Pina Silva Freire****
}

\author{
* Professor(a) Doutor(a). Departamento de Saúde I, UESB \\ ** Cirurgiã-dentista \\ *** Doutor em Biologia e Biotecnologia de Microrganismos, \\ PPGBBM - UESC
}

Recebido em: 20/02/2020. Aprovado em: 24/06/2021

\begin{abstract}
RESUMO
O objetivo desse estudo foi verificar a contaminação microbiológica de resinas compostas utilizadas em uma clínica-escola de Odontologia. Trata-se de uma pesquisa experimental/laboratorial, na qual foram coletadas amostras de 10 bisnagas de resina composta, sendo uma delas o controle negativo. Porções de resina composta contidas no interior das bisnagas foram coletadas e mergulhadas em tubos de ensaio contendo caldo nutriente e posterior semeadura em placas e coloração para caracterizar as colônias e observar bactérias e fungos. Todas as amostras apresentaram contaminação, inclusive o tubo contendo meio de cultura utilizado como controle de manuseio do experimento. Essas contaminações podem ter relação com as falhas dos meios de biossegurança empregados na clínica-escola e com os métodos de transporte e armazenamento das bisnagas de resina composta. Portanto, existe a necessidade de conscientização dos estudantes e docentes para a adoção de medidas de biossegurança específicas para o manuseio das resinas compostas.
\end{abstract}

Descritores: Contenção de Riscos Biológicos. Resinas Compostas. Clínicas Odontológicas. Contaminação Biológica.

\section{INTRODUÇÃO}

O risco de transmissão de doenças infecciosas é inerente à prática da Odontologia ${ }^{1}$. Até o final do ano de 2019, a possibilidade de infecção pelos vírus das Hepatites B e C e da Imunodeficiência Adquirida (HIV) norteavam as estratégias de biossegurança nas clínicas e consultórios odontológicos ${ }^{2}$. Em 11 de março de 2020, a Organização Mundial de Saúde 
declarou situação de pandemia da doença COVID19, causada pelo novo coronavírus denominado SARS-CoV-2 $2^{3}$. A compreensão da evolução da doença indicou que a Odontologia é a profissão com maior risco de contágio. O New York Times publicou em 15 de março de 2020 o artigo "The workers who face the greatest coronavirus risk", no qual descreve que os cirurgiões-dentistas são os trabalhadores mais expostos ao risco de contágio pelo SARS-CoV-2, muito mais do que profissionais das áreas de Enfermagem e Medicina ${ }^{4}$. Esse novo panorama de trabalho levou as equipes a aprimorar suas rotinas e tomar medidas significativas contra essa doença. Várias recomendações para cirurgiõesdentistas e estudantes de Odontologia têm sido publicadas, como maior atenção ao uso de equipamentos de proteção individual, evitar ou minimizar procedimentos que possam produzir gotas ou aerossóis, assim como o uso de sugadores de saliva de baixo ou alto volume para reduzir a produção de gotículas e aerossóis ${ }^{5}$. Dentre os conhecimentos já consolidados pela ciência, tem-se que a transmissão do vírus se dá principalmente por via respiratória, mas também que o vírus pode sobreviver nas mãos, objetos ou superfícies que foram expostas à saliva infectada por algum tempo ${ }^{6}$.

Deter a infecção cruzada nos consultórios odontológicos sempre foi um grande desafio para os cirurgiões-dentistas, pesquisadores e microbiologistas. Muitas vezes os microrganismos conseguem vencer as medidas de segurança adotadas, colocando em risco profissionais e pacientes. Por outro lado, a falta de cuidado de alguns profissionais em relação à biossegurança contribui com a intensificação do ciclo de infecção cruzada no ambiente odontológico ${ }^{6}$.

Alguns materiais de consumo, especificamente a resina composta, encontram obstáculos em relação à biossegurança, visto que não são passíveis de esterilização e desinfecção física ou química ${ }^{7}$. Existem riscos de contaminação tanto do material restaurador quanto da parte externa de suas bisnagas, visto que todas as partes dos objetos, tocadas antes, durante e após o atendimento podem ser fontes de infecção. A presença de microrganismos contidos no interior das bisnagas e em suas embalagens, externamente, somado à manipulação incorreta deste material, podem constituir uma via de infecção cruzada nos consultórios odontológicos ${ }^{8}$.

Dentro deste contexto, verificar a presença de microrganismos na superfície das resinas compostas usadas em uma clínica-escola é importante para propor eventuais medidas de proteção para evitar infecção cruzada e melhorar a segurança para todos os envolvidos no atendimento odontológico. Portanto, o objetivo deste trabalho foi verificar a contaminação das resinas compostas utilizadas em uma clínica-escola de Odontologia.

\section{MATERIAIS E MÉTODO}

Dez bisnagas de resina composta do mesmo fabricante foram utilizadas no estudo, sendo uma delas, ainda lacrada no invólucro original, utilizada como controle negativo, e nove que já haviam sido utilizadas durante os atendimentos, escolhidas aleatoriamente. Todas as bisnagas foram recolhidas com o uso de luvas e pinças estéreis e conduzidas ao laboratório de Microbiologia e Biologia de Microrganismos em embalagens estéreis e fechadas.

As amostras, isoladas do ambiente externo em embalagem estéril, foram levadas ao fluxo laminar e foram inspecionadas. As bisnagas de resina foram destampadas uma a uma e com o auxílio de bisturis estéreis foram coletadas pequenas quantidades da resina localizadas na extremidade da parte interna da bisnaga. A seguir, essas amostras foram mergulhadas em tubos de ensaio contendo meio de 
cultura com caldo nutriente, que permite um amplo crescimento de bactérias e fungos. Foi feita incubação a $37^{\circ} \mathrm{C}$ em câmara com agitação orbital (Shaker KS4000i IKA ${ }^{\odot}$, Staufen, BadenWürttemberg, Alemanha), a 180 rotações por minuto.

Ao todo foram utilizados 11 tubos de ensaio: um contendo somente meio de cultura usado como controle de qualidade do procedimento, a fim de descartar possíveis resultados falso-positivos referentes à má manipulação do material ou contaminação da cabine utilizada. Para isso, esse tubo foi aberto dentro do mesmo fluxo laminar em que as amostras foram manipuladas e submetido ao mesmo processo de destampar/tampar. Dos outros dez tubos, um continha material proveniente da bisnaga de resina que ainda não tinha sido utilizada e nove foram utilizados para a semeadura de material proveniente das resinas em uso na clínica de Odontologia.

Após 24 horas os 11 tubos de ensaio foram inspecionados a fim de observar se houve turvação do meio de cultura e em seguida coletado um inóculo com $100 \mu \mathrm{l}$ de volume total, utilizando micropipetadores com ponteiras novas e autoclavadas, semeados em Agar BHI (Brain Heart Infusion) com auxílio da alça de Drigalski devidamente esterilizada, a fim de realizar a dispersão das colônias por toda a placa. As semeaduras foram repetidas três vezes, a fim de observar reprodutibilidade do teste. Após 24 horas as placas foram analisadas macroscopicamente, a fim de caracterizar as colônias, e posteriormente encaminhadas para realização da coloração de Gram para observação de bactérias, ou lactofenol (azul de algodão) para observação de possíveis fungos.

As colônias foram observadas em microscópio usando a metodologia de Gram e classificadas quanto à sua constituição superficial em positivas ou negativas. Foi observado ainda o arranjo e morfologia das colônias. Para tanto, foram confeccionados esfregaços de colônias isoladas: as lâminas de vidro foram rapidamente passadas na chama do bico de Bunsen, em seguida, com auxílio da alça bacteriológica (alça de platina), foi colocada uma gota de água destilada na lâmina, enquanto a amostra a ser corada foi coletada com auxílio da alça de platina em forma de agulha. Posteriormente, a amostra foi homogeneizada na gota de água destilada colocada previamente na lâmina e deixada para secar. Para garantir a fixação do esfregaço, a lâmina foi rapidamente passada pela chama.

Após a confecção do esfregaço, todo o material posto na lâmina foi coberto com solução cristal violeta por um minuto e lavada rapidamente em água destilada. A seguir, a lâmina foi coberta por lugol, também por um minuto, e em seguida foi novamente lavada. A lâmina foi então inclinada e álcool-acetona ou álcool absoluto foi gotejado por 15 segundos. Mais uma vez a lâmina foi lavada e coberta com fucsina de Gram por 30 minutos. Uma última lavagem em água foi feita e as lâminas foram observadas ao microscópio óptico usando objetiva com aumento de 100x, com auxílio do óleo de imersão.

\section{RESULTADOS}

Com exceção do tubo contendo meio de cultura utilizado como controle de manuseio do experimento, amostras de resinas de todas as bisnagas apresentaram contaminação.

$\mathrm{Na}$ amostra obtida da bisnaga utilizada como controle negativo (nova, nunca aberta) foi encontrada uma grande colônia de forma irregular e aparentemente filamentosa ou algodonosa, com elevação protuberante, opaca, branca e com 
aspecto seco; características sugestivas de um fungo (figura 1a). Em seis bisnagas foram encontradas colônias agrupadas com forma circular, ligeiramente elevadas, com bordas lisas, opacas, esbranquiçadas e viscosas (figuras $1 \mathrm{~b}$ e 1c), todas do mesmo tipo e sugestivas de bactérias. Em três foram encontrados os dois tipos de colônia descritos anteriormente (figura 1d).

Foram confeccionadas lâminas a partir dos cultivos em ágar BHI com coloração azul de algodão para as culturas sugestivas da presença de fungo e coloração de Gram para as sugestivas de bactérias. A colônia mostrada na figura 1a apresentou estrutura microscópica aparentemente leveduriforme (figura 2).

A coloração de Gram revelou a presença de bactérias Gram negativas, com forma de bacilos, tanto isolados quanto em cadeias longas em todas as placas em que houve crescimento bacteriano, bem como cocos isolados (figura 3 ).

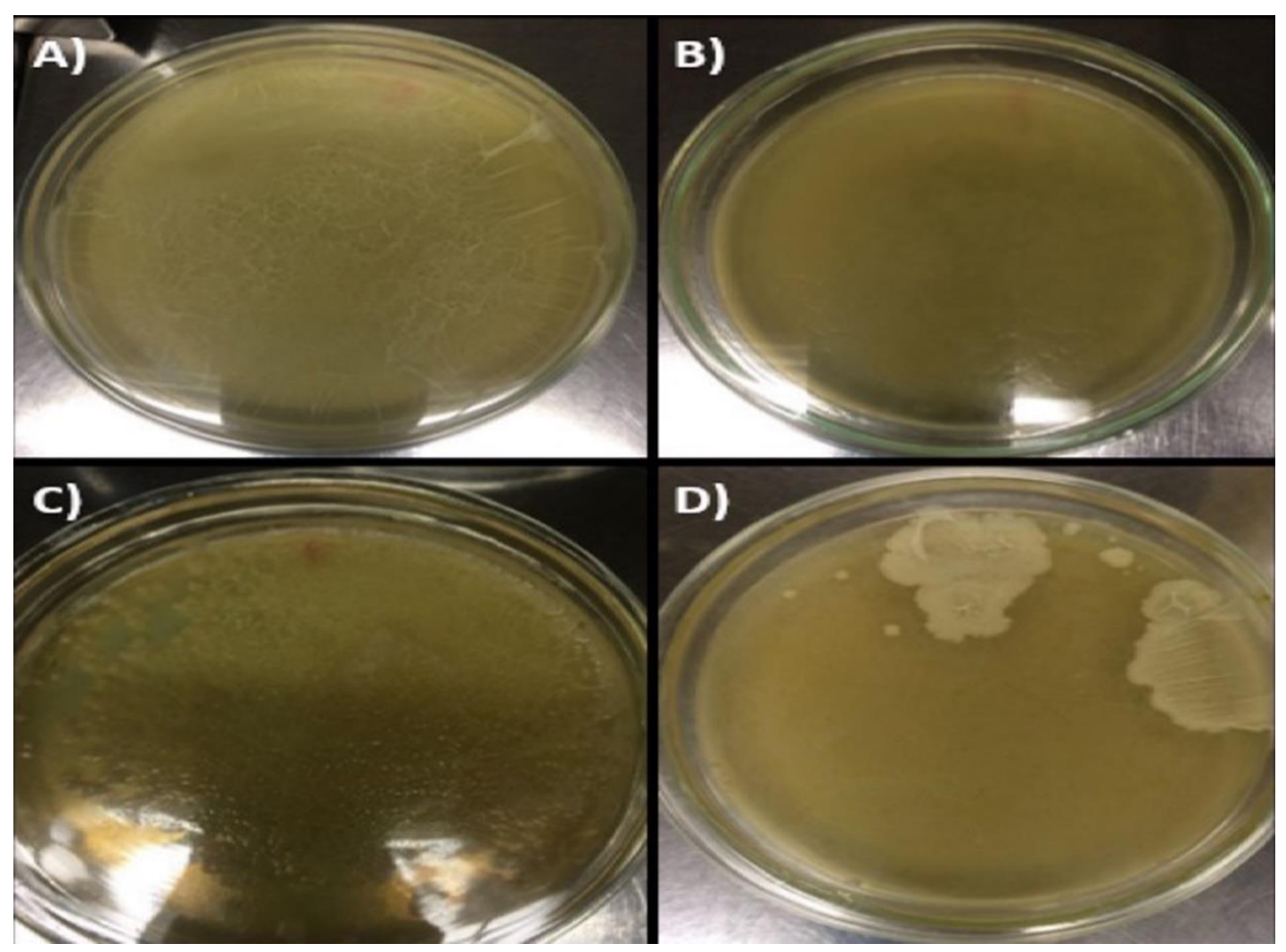

Figura 1. Aspectos morfológicos das colônias encontradas nas placas contendo meio de cultura BHI. Características sugestivas de fungo (a), bactérias (b e c), e ambos (d) 


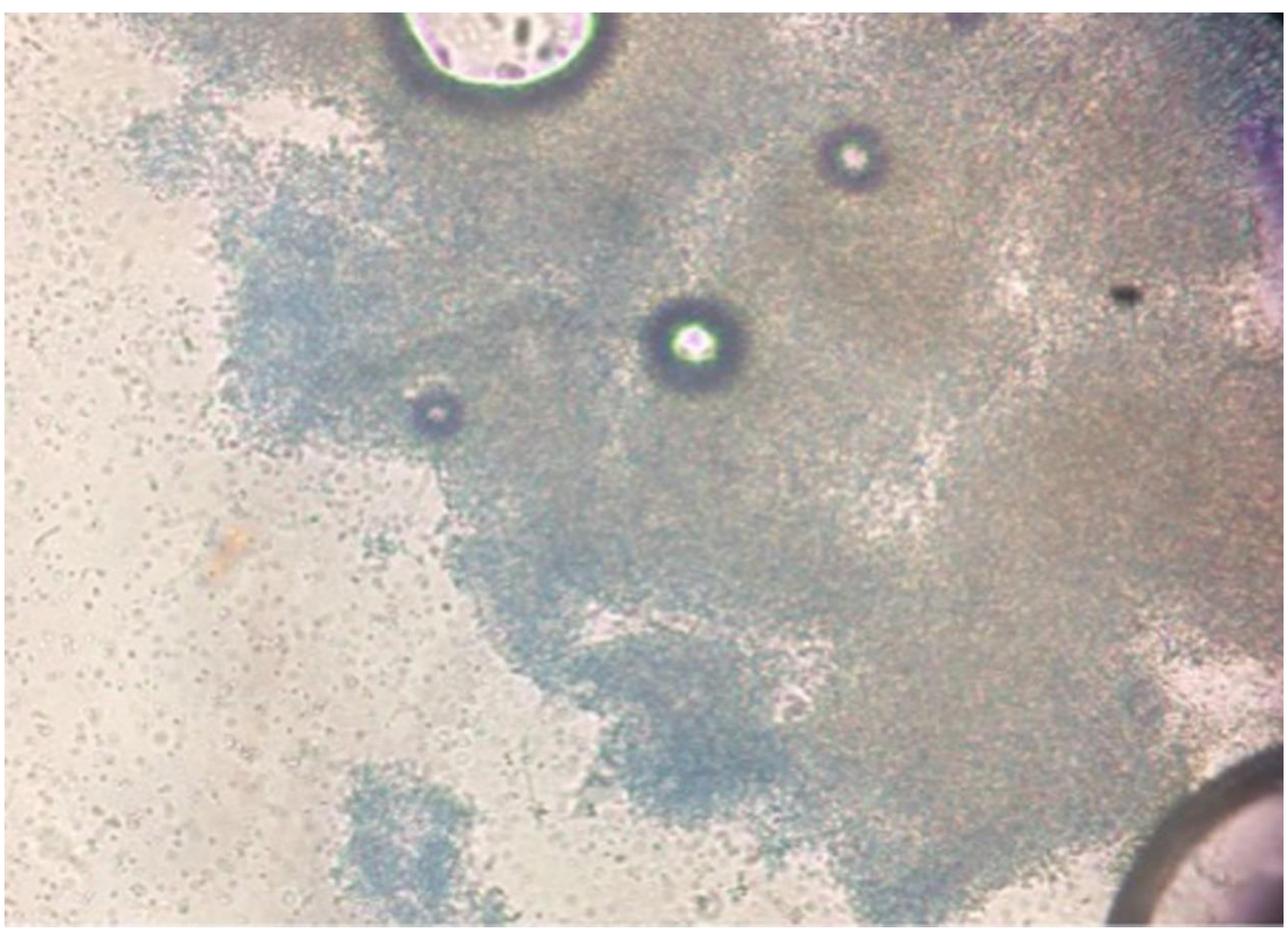

Figura 2. Lâmina confeccionada utilizando corante azul de algodão (lactofenol) demonstrando a possível presença de leveduras. Aumento de 400x

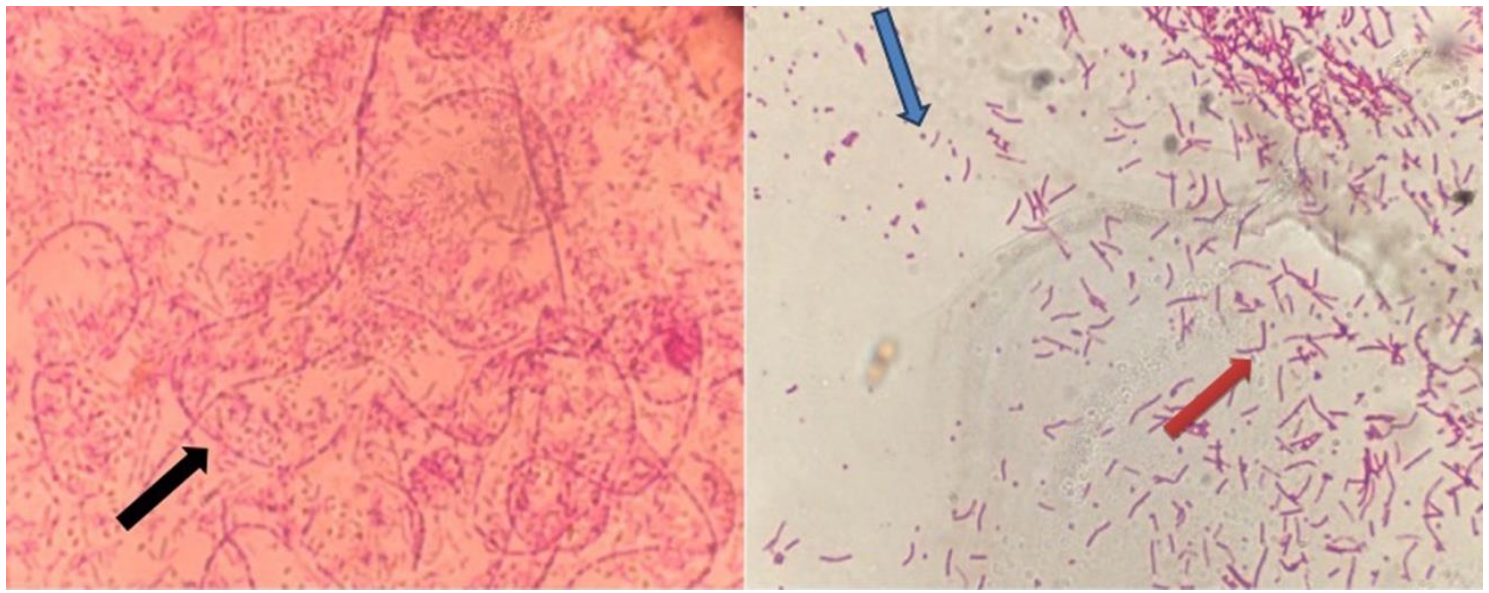

Figura 3. Coloração de Gram demonstrando as bactérias Gram negativas. A seta preta indica os bacilos em cadeias longas, a seta azul mostra os cocos isolados e a seta em vermelho mostra a presença dos bacilos isolados 


\section{DISCUSSÃO}

$\mathrm{O}$ presente estudo demonstrou que houve presença de microrganismos em todas as amostras de resina composta. Na amostra utilizada como controle negativo também foram encontradas colônias, sugerindo uma possível contaminação, o que não era esperado, já que sua embalagem estava devidamente lacrada. Entretanto, para uma afirmação mais assertiva sobre a contaminação encontrada na bisnaga lacrada seria necessária uma amostra maior, bem como uma inspeção do local de armazenagem das resinas e o lote de fabricação, pois todo o processo de distribuição e armazenamento deste material está sujeito à contaminação. Este resultado pode ser explicado devido ao armazenamento a que estas resinas compostas estão submetidas. Segundo o fabricante, esse material deve ser armazenado em local com temperatura entre $2^{\circ} \mathrm{C}$ e $27^{\circ} \mathrm{C}$, longe de luz intensa e de materiais que contenham eugenol. Entretanto, tais procedimentos não foram observados na clínica-escola onde as bisnagas foram coletadas.

Em um experimento realizado nas clínicas de graduação da Faculdade de Odontologia da Universidade Federal de Juíz de Fora (FO/UFJF), com uma amostra de 50 bisnagas de resinas compostas ( 46 como grupo teste e 4 como controle negativo), no qual foi observado o crescimento bacteriano por meio do método de turvação, verificou-se que nas bisnagas utilizadas como controle negativo não houve turvação, e no grupo teste apenas duas bisnagas apresentaram turvação. Entretanto, essa contaminação não representou dados estatisticamente significativos. De acordo com os resultados obtidos, acredita-se que as técnicas de biossegurança empregadas nas clínicas de graduação da FO/UFJF foram eficazes no que diz respeito ao conteúdo das bisnagas de resina composta ${ }^{9}$.

Acredita-se que exista um padrão para o controle de infecção nas instituições de ensino, mas os materiais de uso odontológico são manuseados por diversos estudantes em um curto período de tempo, devendo ser redobrados os cuidados com medidas de prevenção a fim de evitar a contaminação e a infecção cruzada. Não foram encontrados estudos sobre a presença do SARS-CoV-2 na superfície dos materiais de uso odontológico, no entanto, é recomendado que as técnicas restauradoras devam ser realizadas com o uso de isolamento absoluto, realizar a esterilização dos instrumentais odontológicos, paramentação pessoal, com atenção especial ao uso de óculos de proteção e máscara do tipo N95/PFF, desinfecção e proteção de superfície dos materiais coletivos, bem como a desinfecção das espátulas de inserção a cada incremento realizado, visando à proteção das doenças infecto contagiosas ${ }^{6,10}$.

Apesar deste estudo verificar a presença de microrganismos contidos no interior das bisnagas de resina composta, estudos anteriores revelaram alta taxa de contaminação na parte externa das bisnagas do grupo teste. Logo, quando não há a desinfecção externamente, o material restaurador fica suscetível à contaminação, representando um risco à saúde dos pacientes e dos profissionais ${ }^{11,12}$.

Embora o objetivo deste estudo não tenha sido avaliar a microbiota específica encontrada em cada amostra, foi observada uma variedade de formas (cocos, bacilos, isolados, agrupados e leveduras) e colorações (Gram negativo e azul de algodão). Em estudo conduzido por Almeida et al $(2010)^{7}$ foi possível encontrar microrganismos em amostras de resinas compostas, tais como Staphylococcus coagulase-negativo (bactéria), Bacillus sp (bactéria) e Aspergillus (fungo). Esses microrganismos podem ser encontrados na 
microbiota da pele, no meio ambiente e em algumas mucosas, podendo muitas vezes, a depender da carga microbiana, causar infecções.

$\mathrm{Na}$ clínica-escola onde foi coletada a amostra, é preciso adotar medidas que controlem infecção cruzada por meio deste material restaurador. O uso de substâncias desinfetantes na parte externa das bisnagas de resinas compostas, como o álcool $70 \%$, é eficaz contra bactérias Gram positivas e negativas, alguns vírus e fungos, porém, não é capaz de matar esporos ${ }^{13}$. O álcool $70 \%$ em gel foi comparado à clorexidina, sendo que o primeiro demonstrou-se ser mais eficaz apenas contra o Staphylococcus aureus, igualmente eficaz contra Escherichia coli e Streptococcus mutans e menos eficaz em relação à Candida albicans e Enterococcus faecalis ${ }^{14}$.

Foi comprovado que o uso de barreiras, como o Policloreto de Vinila (PVC) aumenta a eficiência do controle de infecção, pois age como uma barreira física e deve ser substituído após cada atendimento de modo que não haja contato direto do operador com a embalagem ${ }^{15}$.

A dificuldade em se controlar a contaminação dos materiais de uso comum é enorme dentro de uma clínica-escola, já que grande quantidade de pessoas se encontra envolvida no processo de atendimento: professores, alunos, funcionários e pacientes. $\mathrm{O}$ importante é conscientizar os envolvidos em seguir as orientações que evitem a quebra da cadeia asséptica e com isso evitem a contaminação cruzada $^{11}$.

A presença de microrganismos encontrados neste estudo pode ser explicada pela quantidade de envolvidos na clínica-escola (pacientes e estudantes). Segundo as evidências encontradas, é sugerido um método biosseguro do uso da resina composta, utilizando casulo ou pote Dappen, em que incrementos são separados anteriormente ao procedimento. Essa proposta torna-se dispendiosa na prática diária de uma clínica escola ${ }^{12}$, além disso, as características do material podem ser alteradas devido a exposição à luz e outras influências ambientais, como o oxigênio ${ }^{16}$, entretanto não deve ser descartada.

Assim, essa e outras medidas como a desinfecção das bisnagas de resina, e proteção com papel filme a cada utilização, deveriam se tornar universais, já que os materiais são manuseados por diversos estudantes num curto período de tempo.

\section{CONCLUSÃO}

Foi verificada a presença de microrganismos em todas as amostras coletadas, incluindo o controle negativo. Essa contaminação pode ter relação com falhas nos procedimentos de biossegurança empregados na clínica-escola, bem como o processo de armazenagem do produto ainda lacrado e sem uso. Portanto, existe a necessidade de conscientização dos alunos e professores para a adoção de medidas de biossegurança específicas para o uso das resinas compostas, assim como medidas que controlem o correto armazenamento deste material.

\begin{abstract}
Microbiological contamination of composite resins used in a Dental school clinic

The aim of this study was to verify the microbiological contamination in composite resins used at one Dental school clinic. This is an experimental/laboratory study, in which samples of 10 tubes of composite resin were collected, one of which was the negative control. Portions of composite resin inside the tubes were collected and dipped in test tubes containing nutrient broth for subsequent seeding on to plates and staining for the characterization of bacterial and fungal colonies. All samples revealed contamination,
\end{abstract}


including the tube containing culture medium used as control for handling the experiment. These contaminations may be related to failures in biosafety measures employed in the Dental school clinic and to the transport and storage methods for the tubes of composite resin. Therefore, it is necessary to raise awareness among students and teachers to adopt specific biosafety measures for the handling of composite resins.

Descriptors: Containment of Biohazards. Composite Resins. Dental Clinics. Biological Contamination.

\section{REFERÊNCIAS}

(1) Thomas MV, Jarboe G, Frazer RQ. Infection control in the dental office. Dent Clin North Am. 2008 Jul;52(3):609-28.

(2) Araujo MW, Andreana S. Risk and prevention of transmission of infectious diseases in dentistry. Quintessence Int. 2002 May;33(5):376-82.

(3) World Health Organization [Internet]. USA: World Health Organization; c2020 [cited 2021, Mar 29] WHO DirectorGeneral's opening remarks at the media briefing on COVID-19. [Acesso em 29 mar. 2021]. Disponível em: https://www.who.int/director-general/ speeches/detail/who-director-general-sopening-remarks-at-the-media-briefingon-covid-19---11-march-2020.

(4) Gamio L. The workers who face the greatest coronavirus risk. The New York Times [Internet]. 2020 mar 15 [Acesso em 29 mar. 2021]. Disponível em: https://www.nytimes.com/interactive/202 0/03/15/business/economy/coronavirusworker-risk.html.

(5) Meng L, Hua F, Bian Z. Coronavirus Disease 2019 (COVID-19): Emerging and future challenges for dental and oral medicine. J Dent Res 2020; 99(9):1113.

(6) Peng X, Xu X, Li Y, Cheng L, Zhou X, Ren B. Transmission routes of 2019-nCoV and controls in dental practice. Int J Oral Sci. 2020; 12(1):9.

(7) Almeida JCF, Prado AKS, Silva WC, Pedrosa SF, Moura MAO, Chaves RM et al. Contaminação de resinas compostas em consultórios odontológicos. ROBRAC. 2010;19(50): 211-5.

(8) Ferraz C, Rocha CG, Rocha MMN, Martins MGA, Jacques P. Contaminação de resinas compostas na prática odontológica. Pesqui Bras Odontoped Clin Integr. 2010; 10(1): 73-8.

(9) Oliveira M, Barreto RM, Salgado IO, Chaves Filho HDM, Diniz CG. Avaliação da contaminação bacteriana em resinas compostas utilizadas nas clínicas de graduação da FO-UFJF. Odontol Clin Cient. 2010; 9(1): 73- 6.

(10) Lages SMR, Santos AF, Silva Junior FF, Costa JG. Formação em odontologia: O papel das instituições de ensino na prevenção do acidente com exposição a material biológico. Cienc Trab. 2015; 17(54): 182-187.

Cardoso CT, Júnior JRP, Pereira EA, Barros LM, Freitas ABDA. Contaminação de tubos de resina composta manipulados sem barreira de proteção. ROBRAC. 2010; 18(48): 71-75.

(12) Montenegro G, Dornas KV, Melo MES, Saldanha RR. Contaminação da parte externa dos tubos de resina composta. Rev Assoc Paul Cir Dent. 2004;58(4):27982. 
B, Barbosa APP, Komiyama EY. Desinfecção de superfície em odontologia: avaliação do álcool gel $70^{\circ}$ INPM, lenços embebidos em solução de clorexidina e spray de cloreto benzalcônio. RGO (Porto Alegre). 2005; 53(2): 151-4.

Aleixo RQ, Queiroz RC, Custódio VC, Moura JA. Contaminação dos tubos de resina composta utilizados na clínica odontológica. ClipeOdonto-UNITAU. 2010; 2(1): 39-45.

(15) Andrade ICGB, Silva Filho HH, Zimath T, Galiassi CD. Avaliação da contaminação microbiológica em resinas compostas utilizadas nas clínicas odontológicas da Universidade Regional de Blumenau. RFO UPF 2018; 22(3):2817.
(16) Yamaji A, Koga K, Tsujimoto A, Shimizu Y, Tsubota K, Takamizawa T, Miyazaki, M. Influence of oxygeninhibited layer on dentin bond strength of chemical-cured resin composite. European Journal of Oral Sciences 2013; 121(5), 497-503.

\section{Correspondência para:}

Haroldo José Mendes

e-mail: hjmendes@uesb.edu.br

Av. José Moreira Sobrinho, s/n, UESB

Departamento de Saúde I - Jequiezinho

45.208-091 Jequié/BA 